\title{
ADOPTION POTENTIAL OF TWO AGROFORESTRY TECHNOLOGIES: IMPROVED FALLOWS AND DOMESTICATION OF INDIGENOUS FRUIT TREES IN THE HUMID FOREST AND SAVANNAH ZONES OF CAMEROON ${ }^{1}$
}

\section{Ann Degrande}

World Agroforestry Centre-West and Central Africa/Humid Tropics

P.O. Box 16317

Yaoundé

Cameroon

e-mail: a.degrande@cgiar.org

\section{BACKGROUND AND OBJECTIVES}

In response to rapidly degrading forests, declining soil fertility and persevering poverty in West and Central Africa, the World Agroforestry Centre (ICRAF) has been looking for agroforestry technologies that can reduce deforestation and soil depletion (ICRAF 2000). From 1987 to 1998, research was oriented towards the development of improved fallow management methods, consisting of planting of fast-growing nitrogen-fixing trees and shrubs that replenish soil

\footnotetext{
${ }^{1} \mathrm{PhD}$-thesis. Faculty of Bioscience Engineering, University of Ghent. $245 \mathrm{p}$.
} 
fertility quicker than the natural vegetation (ICRAF 1995; ICRAF 1996). In 1999, ICRAF reoriented its research in the African Humid Tropics region towards the domestication of indigenous fruit and medicinal tree species with an aim to increase, stabilise and diversify farmers' income and to improve health care in rural areas, while at the same time safeguarding biodiversity and the environment (Tchoundjeu et al. 1999; ICRAF-AHT 2002; ICRAF-AHT 2003). The research approach emphasised farmers' active involvement in the development of new technologies in order to facilitate their adoption.

Assessment of the adoption potential is a key element of a participatory, farmer-centred model of research and development. It improves the efficiency of the technology development and dissemination process, helps document progress made in disseminating new practices, provides farmer feedback for improving research and extension programmes, and helps to identify the policy and other factors contributing to successful technology development programmes as well as the constraints limiting the achievements (Franzel et al. 2001).

The main objective of the present study was to assess adoption potential of agroforestry technologies by farmers in the humid forest and savannah zones of Cameroon and to suggest means to ameliorate and accelerate adoption.

Inspired by literature on "innovation-decision processes" and "adoption of innovations" (Rogers 1995; Reed 2001; Franzel et al. 2002; Place and Swallow 2002), different aspects affecting adoption of agroforestry technologies were studied:

- Characteristics of the technologies themselves, i.e. biophysical performance and technical requirements, complexity, profitability, acceptability and users' perception of benefits and disadvantages, relevance and compatibility;

- Existing land-use systems and farmers' livelihood strategies in order to determine entry points for the proposed innovations. 
In addition, a closer look was given to the participatory approach of the research and development of new agroforestry technologies with an aim of improving methodologies.

\section{METHODOLOGY}

Approaches used to assess the adoption potential of agricultural practices have evolved considerably in the last couple of decades (Franzel et al. 2002). Today's understanding of the process of innovation-decision and adoption calls for a holistic view of dynamic farmer needs, objectives, personal characteristics, capital assets and communication, in addition to the technological characteristics of the innovations themselves (Rogers 1995; Reed 2001). Franzel et al. (2002) argue that assessing the adoption potential of the technology involves determining its biophysical performance under farmer's conditions, its profitability and its acceptability to farmers.

This study combined various research methods and tools, both quantitative and qualitative, to get a holistic view of the biophysical and socio-economic context in which farmers make the decision whether to adopt or reject the proposed agroforestry technologies. First, we focused on understanding farmers' livelihoods and the broader context in which farmers earn their living, using the sustainable livelihoods framework (DFID 1999). To evaluate the performance of the agroforestry technologies under a wide range of conditions, collaborative adaptive research was carried out in farmers' fields and nurseries. Feedback about constraints in the establishment and maintenance of the improved technologies, as well as farmers' perceptions on advantages, disadvantages and the spread of the technologies was gathered through socio-economic surveys. Net financial benefits were calculated in order to determine the profitability of the technologies to farmers. As part of the evaluation, we also studied participation of vulnerable groups in agroforestry pilot groups and identified specific constraints that these categories face in adopting the proposed technologies. Finally, ex-ante impact assessment workshops were held with stakeholders in order to obtain farmers' views on impact indicators and to elicit their expectations of magnitudes of impact and constraints in achieving these levels. 


\section{FARMER LIVELIHOODS}

Tree-crop or forest-based farming systems in the humid forest and savannah areas of Cameroon were, until recently, highly dependent on cocoa and coffee. This made farmers extremely vulnerable to fluctuations in world market prices. Consequently, farmers turned their attention to food cropping, thereby opening up, where possible, new forest land and shortening fallow periods elsewhere. This inevitably led to soil fertility problems, whereas rural households were still suffering from seasonality effects and cash shortages, due to the low added value of food crops. To address these two problems, poverty reduction strategies must thus focus on: (1) raising agricultural and natural resource productivity through the generation and dissemination of improved technologies and, (2) diversifying income sources in order to reduce dependency on few crops that are prone to price fluctuations and to smoothen seasonal fluctuations in income and consumption. However, the Central African region in general and southern Cameroon in particular, faces some major weaknesses that impede or, at least slow down research and development efforts. These include a weak human capital base, degradation of the natural resource base, insufficient and poorly maintained rural infrastructure and inappropriate pro-poor policies and institutions. 


\section{IMPROVED TREE AND SHRUB FALLOWS}

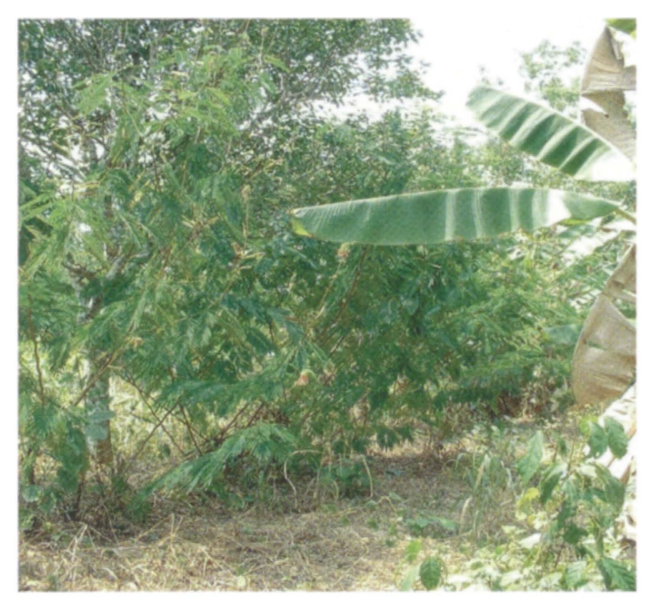

Hedge of calliandra trees left to fallow for about 2 years

Declining soil fertility was identified during a diagnosis in the humid tropics of Cameroon by researchers and developers as a problem area that agroforestry could address. Between 1988 and 1998, ICRAF's research activities thus focused on developing and testing with farmers improved fallow systems using $\mathrm{N}$-fixing trees and shrubs that would replenish soil fertility quicker than natural fallows. Despite satisfactory biophysical performance of tree fallows compared to natural fallows on-station, farmers' interest in the technology remained low. Major reasons were very modest yield increases under farmers' conditions $(<40 \%)$ and low profitability of the technology, because of high upfront costs for tree establishment and important labour requirements for tree management. In addition, hedgerow intercropping was originally designed to solve 3 main problems, i.e. low soil fertility, risk of soil erosion and lack of fodder, diagnosed by researchers and extensionists. However, most farmers in the study sites do not yet perceive them as major production constraints. 


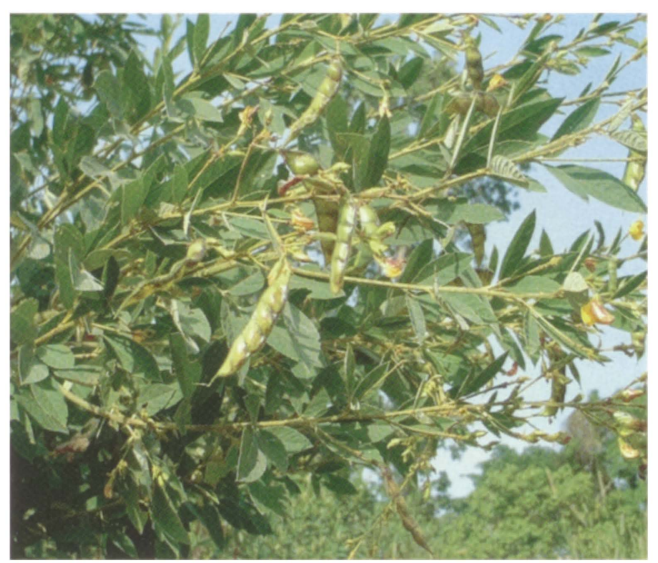

Cajanus cajan: N-fixing shrub used in improved fallows.

Grains are an excellent source of proteins

Shrub fallows with Cajanus cajan, on the other hand, have proven to increase crop yields more significantly both on-station and under farmer management. Furthermore, cost-benefit analysis demonstrated the profitability of the technology, which indicates higher adoption potential than tree fallows. The technology is particularly interesting to households with insecure land tenure and to women, because Cajanus fits better into their cropping system.

While many farming households in southern Cameroon still have enough land to practise natural fallows, from a scientific point of view and in the interest of society, soil fertility improving technologies are urgently needed to avoid further soil nutrient loss and degradation. However, farmers' short-term horizon (or high discount rate) makes it difficult to incorporate soil fertility enhancement in their livelihood strategies. The main challenge here is to link the solution of unperceived or low priority problems to the solution of perceived, high priority problems. For example, tree fallows in the short term provide by-products or services that are appreciated by farmers. Our study has shown that farmers adopt tree fallows in the first place because of the additional benefits (honey, stakes, fuel wood and weed 
suppression) and not for soil fertility improvement per se. Comparing adoption of improved fallows in countries with different stages of agricultural intensification, southern Cameroon presents an intermediate situation where increasing pressure on agricultural land leads to declining fallowing periods. This is a stage where adoption potential of improved fallows is likely to grow in the near future. Therefore, there is an urgent need to raise farmers' awareness on the benefits of improved fallows through demonstration plots, field days, study visits, technical manuals, etc., especially in those areas where fallow periods are rapidly shortening, where soils are poor and where weed incidence is a serious problem. At the same time, seed-production units should be established at different levels, as lack of planting material is a major bottleneck to the wider adoption of improved fallows.

\section{AGROFORESTRY TREE DOMESTICATION}

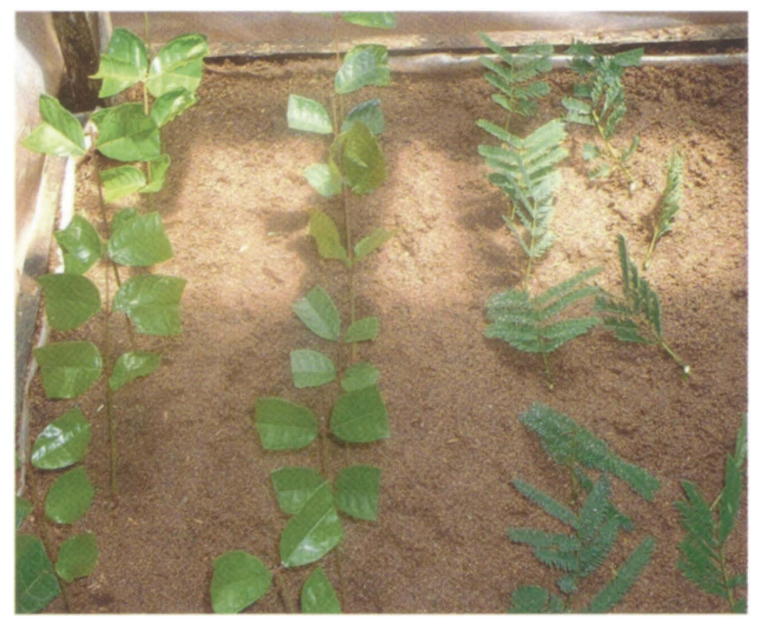

Cuttings from Dacryodes edulis and Calliandra calothyrsus in a non-mist rooting propagator

Evidence today indicates that strategies to combat poverty in the humid tropics of West and Central Africa should not only tackle problems of shortening fallows and declining soil fertility, but also reduce farmers' vulnerability and dependence on a few cash crops. 
Domestication of local fruit and medicinal trees is expected to contribute to increase and to diversify households' income. Our study focuses on the first stages of tree domestication, i.e. tree selection and propagation, because we do not yet have sufficient information on subsequent phases, i.e. tree integration and marketing. Evaluation of vegetative propagation in farmer pilot nurseries in the humid forest and savannah zones of Cameroon showed that farmers are able to propagate a number of agroforestry species, either through rooting of cuttings or marcotting. Farmers appreciate vegetative propagation because the techniques present several advantages compared to propagation by seeds, for example shorter trees that fruit early and reproduction of trees with desired traits (exact copies of mother tree).

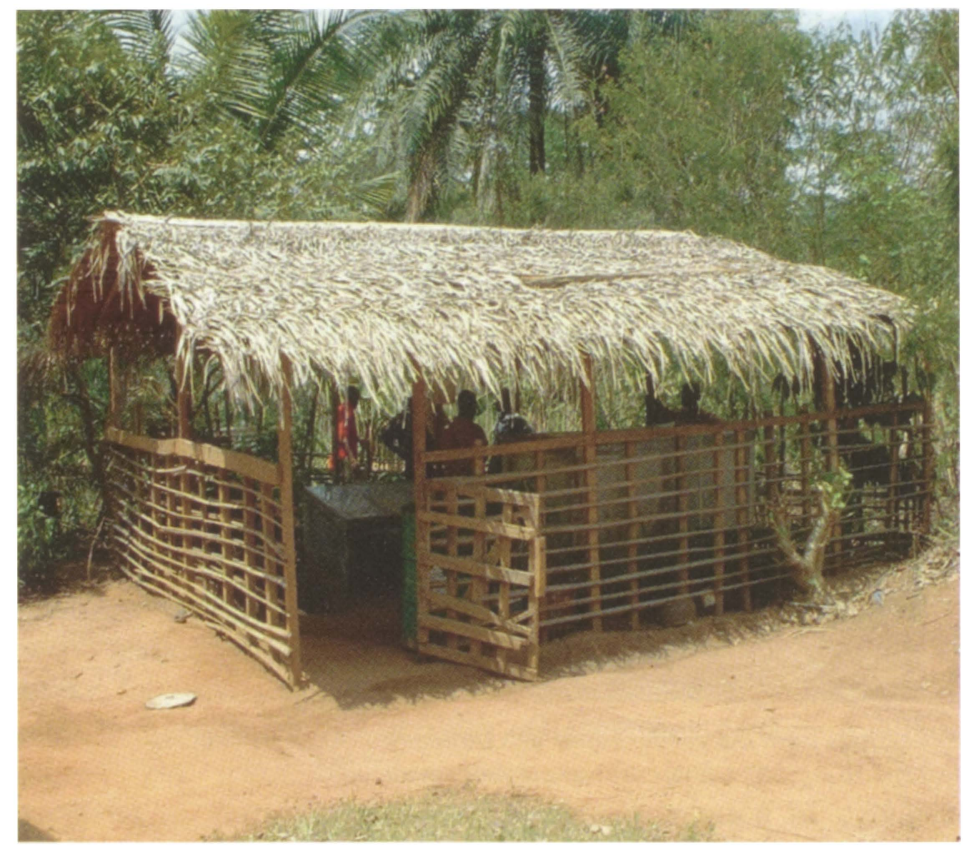

A farmer-managed vegetative propagation unit, roofed with traditional thatches in Nkom-Efoufoum, humid forest zone, Cameroon 
However, wide-scale adoption of vegetative propagation is likely to be constrained by the cost of nursery infrastructure and materials, although cost-benefit analysis shows that farmer-managed vegetative propagation units are profitability provided infrastructure is used to full capacity and about $75 \%$ of the produce can be effectively sold. Measures to enhance adoption potential would thus include reducing nursery costs and increasing production of improved propagules. Cost reduction would also enhance participation of vulnerable groups in tree domestication activities, although appropriate communication messages and channels remain a must if these categories are to be fully involved.

\section{RECOMMENDATIONS}

Based on the above results, the study concludes by identifying further research needs and formulating recommendations for development and policy actions with an aim to enhance adoption of improved fallows and tree domestication in the humid forest and savannah zones of Cameroon. Apart from ensuring tree and shrub germplasm supply, research on improved fallows should focus on their sustainability and look at other complementary soil amending measures. Dissemination of improved fallows should be targeted to areas with shortening fallow periods, where soils are poor and where weed incidence is a serious problem.

Related to tree domestication, international research should focus on the development of "domestication strategies" for model species, so that national research systems and other clients could easily apply them to the multitude of agroforestry species of interest to farmers.

Other research topics still to be looked into are integration options for improved propagules and marketing of agroforestry trees and tree products.

One of the major outcomes of this study is the fact that agroforestry, as an ecologically sound and economic viable option for small-scale farmers, has long been neglected by developers. This is in part due to the multidisciplinary and multi-institutional nature of agroforestry, which makes it to fall between the gaps of institutions. As a result, extension agents are usually ill prepared to disseminate agroforestry 
innovations in the field. We therefore argue that more active involvement of extensionists in the development of agroforestry innovations, using a participatory approach, will facilitate subsequent dissemination on scale.

\section{BIBLIOGRAPHY}

DFID, 1999. Sustainable Livelihoods guidance sheets. Department for International Development, UK.

FRANZEL, S., COE, R., COOPER, P., PLACE, F. \& SCHERR, SJ., 2001. Assessing the adoption potential of agroforestry practices in sub-Saharan Africa. Agricultural Systems 69: p. 37-62.

FRANZEL, S., SCHERR, SJ., COE, R., COOPER, P.J.M. \& PLACE, F., 2002. Methods for assessing agroforestry adoption potential. In: Franzel, S. \& Scherr, SJ., (eds.), 2002. Trees on the Farm. Assessing the Adoption Potential of Agroforestry Practices in Africa. CAB International in association with ICRAF. p. 11-36.

ICRAF. 1995. Annual Report 1995. International Centre for Research in Agroforestry, Nairobi, Kenya: 288 p.

ICRAF 1996. Annual Report 1996. International Centre for Research in Agroforestry, Nairobi, Kenya. 340 p.

ICRAF. 2000. Paths to prosperity through agroforestry. ICRAF's Corporate Strategy 2001-2010. International Centre for Research in Agroforestry, Nairobi, Kenya. September $2000.43 \mathrm{p}$.

ICRAF-AHT. 2002. Annual Report 2001-2002. International Centre for Research in Agroforestry-African Humid Tropics Regional Programme. Yaoundé, Cameroon.

ICRAF-AHT. 2003. Annual Report. World Agroforestry Centre, ICRAF-African Humid Tropics Regional Programme. Yaoundé, Cameroon.

PLACE, F., \& SWALLOW, B., 2002. Chapter 3: Assessing the Relationships between Property Rights and Technology Adoption in Smallholder Agriculture: Issues and Empirical Methods. In: Meinzen-Dick, R, Knox, A, Place, F. \& Swallow, B (eds). Innovation in Natural Resource Management. The Role of Property Rights and Collective Action in Developing Countries. IFPRI. The Johns Hopkins University Press. Baltimore and London. p. 45-72.

REED, M.S., 2001. Participatory technology development for agroforestry: an innovation-decision approach. Centre for Environmental Management Working Paper R01/121. University of Leeds, UK.

http://www.env.leeds.ac.uk/rmreed/Reed\%202001.doc. 
ROGERS, R., 1995. Diffusion of Innovations. Fourth Edition. The Free Press, New York, USA. 519 p.

TCHOUNDJEU, Z., DUGUMA, B., TIENTCHEU, M.L., \& NGO-MPECK, M.L., 1999. Domestication of indigenous agroforestry trees: ICRAF's strategy in the humid tropics of West and Central Africa. In: Sunderland, T.C.H., Clark, L.E., \& Vantomme, P., (eds), 1999. Non-wood forest products of Central Africa. Current research issues and prospects for conservation and development. Based on the outcome of the International Expert Meeting on NWFP in Central Africa, held at Limbe Botanic Garden, Cameroon. 10-15 May 1998. p. 161-170. 